\title{
Real or perceived adverse effects of vaccines and the media- tale of our times
}

\author{
"In postmodern medicine, risks and adverse effects will receive a \\ much higher priority"1
}

To users, adverse effects of healthcare interventions are made up of a perception of exposure to risk, its consequences and the way that information on these is communicated. The story of measles mumps and rubella (MMR) vaccine is a good example of this contemporary paradigm.

In 1998 Wakefield and colleagues described a series of cases of 12 children aged 3 to 10 years affected by chronic enterocolitis and regressive developmental disorder. ${ }^{2}$ Nine of the 12 children had received MMR vaccine within the previous month. Wakefield and colleagues postulated a possible association of these entities with MMR vaccination. ${ }^{2}$ This work followed an earlier study by Miyamoto et $a \mathrm{l}^{3}$ and Ekbom et $a l^{4}$ who suggested MMR vaccination as a possible risk factor for Crohn's disease. The subsequent onset of autism, the authors suggested, could be attributable to disorders of absorption or breakdown of gut derived peptides, or both, leading to a disruption of normal neuroregulation and brain development.

Since the publication of the Wakefield study on 28 February 1998 public concern fuelled by extensive media coverage, caused a steady decline in MMR coverage in parts of the United Kingdom, with a subsequent risk of a decline in heard immunity and resurgence in morbidity.

A swift reaction by the UK Government ${ }^{5}$ and the subsequent publication of studies by the Committee on Safety of Medicines $^{6}$ and by Taylor et al showing no evidence of a causal link partly redressed the balance. As usual with vaccine "scare stories", there was a delay between publication of the initial case series and that of population-based causal assessment study. During this time declining coverage took place.

In this issue of the journal, Mason and Donnelly report the results of an ecological study comparing MMR coverage rates in distribution areas of the South Wales Evening Post (SWEP) with areas in which no exposure to the SWEP had taken place. ${ }^{8}$ During the period July to September 1998, in the midst of a focused anti-MMR campaign by the SWEP, the decline in coverage in SWEP area was over four times that of the rest of Wales. The campaign reflected some of emotionally charged headlines in UK, in the rest of Europe and North America.

Mason and Donnelly appear to have published the first study assessing direct impact of one form of mass media on the uptake of immunisation, in a specified territory. ${ }^{8}$

The MMR saga and the study by Mason and Donnelly raise a series of points that the scientific community must resolve.

Vaccination campaigns are particularly prone to allegation of cause and effect relations. In most cases the claimed adverse effect of the vaccine or vaccines is a nosological entity of increasing prevalence but of unknown causation (such as multiple sclerosis or autism).

Other factors contribute to increase the emotion of such claims. Immunisation programmes involve large numbers of healthy children and are invariably state sponsored. In some European states, law regulates vaccination campaigns and parents cannot refuse to have their children immunised. The impact on parents of a perceived causal link with a chronic disease that could threaten the life and wellbeing of their children is understandably great. Inevitably, in a proportion of cases the worry and emotion spills over into a threat of legal action against governments, manufacturers or individuals. This has the effect of taking the matter outside the scientific and healthcare arena and into the realm of the judiciary.

Is this trend likely to decline? In his masterly essay on postmodern medicine, Gray warns us that a distrust of science, a greater attention to risk, better access to real-time information and a readiness to recur to the judiciary are all factors of a postmodern society. ${ }^{1}$ Facts bear this assessment out. A report on vaccine vigilance written for the European Commission in 1997 lists the addresses of 14 web sites dealing with the adverse effects of childhood vaccination. ${ }^{9}$ This is likely to be a considerable underestimate. The list of alleged causal associations is endless, with only a minority of associations having been assessed and found to have evidence to support the claim.

Two authoritative reviews carried out by the USA's Institute of Medicine on the safety of childhood vaccination concluded that two thirds of the 76 alleged vaccine adverse events fell in the categories of no data or inadequate data to make assessment of causality. ${ }^{10}{ }^{11}$

As we are likely to be called with increasing frequency to assess causal associations, are our methodological tools up to the job? The answer is: not quite. The EU Report concluded that the five current methods of vaccine vigilance (case reports, case-control studies, active and passive surveillance and randomised controlled trials) are insufficient and further developmental work should be undertaken.

Three priorities emerge:

(1) A need for robust and universally applied definitions of cases and alleged or real adverse events.

(2) A requirement for better epidemiological information on the diseases in question including the disease profile, its incidence, and prevalence.

(3) A need for effective and rapid communication of current knowledge on the alleged causal link.

The first two are within the traditional remit of the scientific community and could be achieved with a coordinated effort by all stakeholders in the evaluation of the safety of vaccines.

The need for good communications is perhaps the most delicate and newest aspect of the problem. As the study by Mason and Donnelly shows, communication is the key to the launch and maintenance of successful vaccination campaigns.

One possible model for such an effort is the Vaccine Safety Datalink project at the Centre for Disease Control and Prevention (CDC), in the USA. ${ }^{12}$ The project has computerised vaccine exposure and outcome data on more than half a million American children and is able to respond relatively rapidly to public concerns. A public information programme is an integral part of the project. 
The scientific community should develop new methods for the evaluation of the safety of vaccines to complement existing ones and maintain updated cumulative reviews of evidence by drawing from all data sources. Recognition of public concern on a specific issue would then trigger the dissemination of the evidence and its interpretation to relevant parties.

There is no bigger and most rewarding task for the vaccine community at the start of the new century.

TOM JEFFERSON

Cochrane Vaccines Field, UK Cochrane Centre, Summertown Pavilion,

Middle Way, Oxford OX2 7LG (e-mail: tjefferson@cochrane.co.uk)

The author would like to acknowledge the help received by Drs Robert Chen, Ulrich Heininger, Elisabeth Loupi, and Harald Hejbel. Mistakes and opinions are the author's.

1 Gray JAM. Postmodern medicine. Lancet 1999;354:1550-3.

2 Wakefield AJ, Murch SH, Anthony A, et al. Ileal-lymphoid-nodular hyperplasia, non specific colitis and pervasive developmental disorder in hyperplasia, non specific colitis and
children. Lancet 1998;351:637-41.
3 Miyamoto $\mathrm{H}$, Tanaka $\mathrm{T}$, Kitamoto $\mathrm{N}$, et al. Detection of immunereactive antigen with monoclonal antibody to measles virus in tissue from patients antigen with monoclonal antibody to measles virus
with Crohn's disease. $\mathcal{F}$ Gastreonterol 1995;30:28-33.

4 Ekbom A, Wakefield AJ, Zack M, et al. Crohn's disease following early measles exposure. Lancet 1994;34:508-10.

5 Department of Health. MMR Vaccine is not linked to Crohn's disease or autism. Circular 98/109, 24 March 1998. London: Department of Health.

6 Committee on Safety of Medicines. Report of the Working Party on MMR vaccine London: May 1999.

7 Taylor B, Miller E, Farrington CP, et al. Autism and measles, mumps and rubella vaccine: no epidemiological evidence for a causal association. Lancet 1999;353:2026-9.

8 Mason BW, Donnelly PD. Impact of a local newspaper campaign on the uptake of the measles mumps and rubella vaccine. F Epidemiol Community uptake of the measles
Health 2000;54:473-4.

9 Rawlins MD, Fracchia GN, Payne S, et al. Vaccinevigilance: Report of an Expert Group. Report of the discussions on Vaccinevigilance of an Expert Group convened in Brussels on 27 May 1997 at the initiative of the European Pharmacovigilance Research Group (EPRG), a group of experts in pharmacovigilance research issues sponsored by the European Commission - DGXII. Brussels: EU, 1998

10 Howson CP, Howe CJ, Fineberg HV, eds. Adverse effects of pertussis and rubella vaccines. Washington DC: National Academy Press, 1991.

11 Stratton KR, Howe CJ, Johnston RB, eds. Adverse events associated with childhood vaccines. Washington DC: National Academy Press, 1994.

12 Chen RT, Glasser JW, Rhodes PH, et al. Vaccine Safety Datalink project: a new tool for imporoving vaccine safety monitoring in the United States. Pediatrics 1997;99:765-73. 